\title{
Structured Reporting of Acute Ischemic Stroke - Consensus-Based Reporting Templates for Non-Contrast Cranial Computed Tomography, CT Angiography, and CT Perfusion
}

\section{Strukturierte Befundung beim ischämischen Schlaganfall: Konsensbasierte Befundvorlagen für die native Computertomografie, CT-Angiografie und CT-Perfusion des Neurokraniums}

Authors

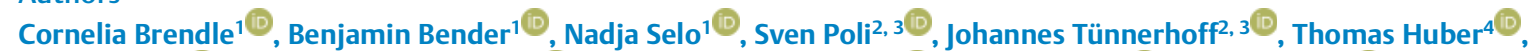
Jan Kirschke ${ }^{5 \mathbb{D}}$, Tobias Boeckh-Behrens ${ }^{5}$, Daniel Pinto dos Santos ${ }^{6}$, Roland Wiest $^{7}$, Ansgar Berlis ${ }^{8}$, Thomas Liebig $^{90}$, Oliver Korczynski ${ }^{10}$, Ulrike Ernemann ${ }^{1}$, Johann-Martin Hempel ${ }^{1}$

Affiliations

1 Radiologische Universitätsklinik Tübingen, Abteilung Diagnostische und Interventionelle Neuroradiologie, Tübingen, Deutschland

2 Universitätsklinikum Tübingen, Abteilung Neurologie mit Schwerpunkt neurovaskuläre Erkrankungen, Tübingen, Deutschland

3 Universitätsklinikum Tübingen, Hertie-Institut für klinische Hirnforschung, Tübingen, Deutschland

4 Universitätsmedizin Mannheim, Klinik für Radiologie und Nuklearmedizin, Mannheim, Deutschland

5 Klinikum rechts der Isar, Technische Universität München, Neuro-Kopf-Zentrum, Abteilung Diagnostische und Interventionelle Neuroradiologie, München, Deutschland

6 Uniklinik Köln, Institut für Diagnostische und Interventionelle Radiologie, Köln, Deutschland

7 Inselspital Bern, Universitätsinstitut für Diagnostische und Interventionelle Neuroradiologie, Bern, Schweiz

8 Universitätsklinikum Augsburg, Klinik für Diagnostische und Interventionelle Neuroradiologie, 8

Universitätsklinikum Augsburg, Klinik für Diagnostische und Interventionelle Neuroradiologie, Augsburg, Deutschland

9 Ludwig-Maximilians-Universität München, Institut für Diagnostische und Interventionelle Neuroradiologie, Klinikum Großhadern, München, Deutschland

10 Universitätsmedizin Mainz, Klinik und Poliklinik für Neuroradiologie, Mainz, Deutschland

Key words

structured reporting, ischemic stroke, computed tomography

received 24.03.2021

accepted 06.04.2021

published online 15.07.2021
Bibliography

Fortschr Röntgenstr 2021; 193: 1315-1317

DOI 10.1055/a-1487-6849

ISSN 1438-9029

(C) 2021. Thieme. All rights reserved.

Georg Thieme Verlag KG, Rüdigerstraße 14,

70469 Stuttgart, Germany

Correspondence

Dr. Johann-Martin Hempel

Department of Diagnostic and Interventional Neuroradiology,

Eberhard-Karls-Universität Tübingen Medizinische Fakultät,

Hoppe-Seyler-Str. 3, 72076 Tübingen, Germany

Tel.: $+49 / 7071 / 2968568$

johann-martin.hempel@uni-tuebingen.de

$\bigoplus \begin{aligned} & \text { Supplementary material is available under } \\ & \text { https://doi.org/10.1055/a-1487-6849 }\end{aligned}$

\section{ABSTRACT}

Purpose Structured reporting is an essential step in establishing standardized quality standards in diagnostic radiology. The German Society of Radiology and the German Society of Neuroradiology aim to provide templates for the structured reporting of different radiological examinations. Method The Information Technology working group of the German Society of Radiology developed structured templates for the radiological reporting of different indications in consensus with specialist support by experts.

Results We present a template for the structured reporting of examinations of patients with acute ischemic stroke by non-contrast computed tomography, CT angiography, and $\mathrm{CT}$ perfusion. This template is provided on the website www.befundung.drg.de for free use.

Conclusion Implementation of the structured template may increase quality and provide a minimum standard for radiological reports in patients with acute ischemic stroke. 


\section{Key Points:}

- The German Society of Radiology and the German Society of Neuroradiology are providing support for the development of structured templates in German.

- We present a template for the structured reporting of examinations of patients with acute ischemic stroke by non-contrast computed tomography, CT angiography, and CT perfusion. This template is provided on the website www.befundung.drg.de for free use.

- Implementation of the structured template may increase quality and provide a minimum standard for radiological reports in patients with acute ischemic stroke.

\section{Citation Format}

- Brendle C, Bender B, Selo N et al. Structured Reporting of Acute Ischemic Stroke - Consensus-Based Reporting Templates for Non-Contrast Cranial Computed Tomography, CT Angiography, and CT Perfusion. Fortschr Röntgenstr 2021; 193: 1315-1317

\section{ZUSAMMENFASSUNG}

Hintergrund Die strukturierte Befundung ist ein wichtiger Bestandteil zur Verbesserung des Qualitätsstandards in der radiologischen Diagnostik. Die Deutsche Röntgengesellschaft und die Deutsche Gesellschaft für Neuroradiologie sind bestrebt, der Fachöffentlichkeit standardisierte Befundvorlagen für spezifische Fragestellungen zur Verfügung zu stellen. Methode Die AG Informationstechnologie der Deutschen Röntgengesellschaft hat in Zusammenarbeit mit fachspezifischen Experten im Konsensverfahren Befundvorlagen für verschiedene radiologische Fragestellungen erarbeitet.

Ergebnisse Die hier vorgestellte strukturierte Befundvorlage zur computertomografischen Akutdiagnostik des ischämischen Schlaganfalls mittels nativer Computertomografie (CT), CT-Angiografie und CT-Perfusion wird online unter www.befundung.drg.de in einer frei zugänglichen Datenbank zur Verfügung gestellt und kann über strukturierte-befun dung@drg.de bzw. https://github.com/DRGagit/ak_befun dung kommentiert werden.

Schlussfolgerung Der Einsatz der strukturierten Befundvorlage soll einen Beitrag zur Steigerung der Qualität radiologischer Befunde und die Einhaltung eines Mindeststandards bei der Akutdiagnostik des Schlaganfalls leisten.
Structured reporting is an essential step in establishing quality standards in diagnostic radiology. This type of reporting uses standardized templates tailored to specific medical issues. It differs from the free-form texts that are currently most commonly used for reporting in the clinical routine.

Structured reporting provides a greater degree of completeness and thus better report quality [1-5]. According to multiple studies, most clinical referring physicians prefer structured reporting to free-form texts [6-8]. The primary goal of a structured reporting template is to provide a high-quality radiology report for a specific radiological examination in accordance with the current state of knowledge. Structured reporting templates are typically created in consensus with specialist support provided by radiology and clinical experts.

Structured reporting complements imaging schemes that are already established in the determination of the further clinical approach, such as the Alberta Stroke Program Early Computed Tomography (CT) Score (ASPECTS), which is used in neuroradiology for stroke treatment, or the Response Assessment in Neuro-Oncology (RANO) criteria, which are used for evaluating the treatment of brain tumors $[9,10]$. They are an important component of evidence-based medicine, which requires guideline-based diagnostic workup and treatment, standardized clinical workflows, and quality assurance. Structured reporting also facilitates scientific and computer-based further usage of radiology data [1, 11].

According to a number of large radiology societies, the improvement of report quality by using structured reporting is a high priority $[11,12]$. Consequently, the Radiological Society of North America (RSNA) created the Radlex, a lexicon of standard radiology terminology that is now also available in German at https://www.drg.de/de-DE/4291/radlex-deutsch/ [13]. Moreover, the RSNA and the European Society of Radiology (ESR) created the free platform www.radreport.org, which provides standardized reporting templates for various radiological examinations in HTML-5 or IHE-MRRT format.

The German Society of Radiology and the German Society of Neuroradiology are providing support for the development of structured templates in German. In collaboration with the various working groups of the German Society of Radiology and the German Society of Neuroradiology, the Information Technology working group (@GIT) is creating, validating, and certifying specialty- and case-specific templates in consensus. The structured reporting template presented here for examinations of patients with acute ischemic stroke by non-contrast computed tomography, CT angiography, and CT perfusion is provided online at www.befundung.drg.de in a free database and comments can be added at strukturierte-befundung@drg.de or https://github.com/ DRGagit/ak_befundung.

\section{Conflict of Interest}

Thomas Huber ist neben seiner im Manuskript genannten Affiliation bei der Firma Smart Reporting GmbH beschäftigt. Ansonsten bestehen keine wirtschaftlichen oder persönlichen Verbindungen im o.g. Sinne.

\section{References}

[1] Pinto Dos Santos D, Hempel JM, Mildenberger P et al. Structured Reporting in Clinical Routine. Rofo 2019; 191: 33-39 
[2] Bink A, Benner ], Reinhardt ] et al. Structured Reporting in Neuroradiology: Intracranial Tumors. Front Neurol 2018; 9: 32

[3] Rocha DM, Brasil LM, Lamas JM et al. Evidence of the benefits, advantages and potentialities of the structured radiological report: An integrative review. Artif Intell Med 2020; 102: 101770

[4] Norenberg D, Sommer WH, Thasler W et al. Structured Reporting of Rectal Magnetic Resonance Imaging in Suspected Primary Rectal Cancer: Potential Benefits for Surgical Planning and Interdisciplinary Communication. Invest Radiol 2017; 52: 232-239

[5] Maros ME, Wenz R, Forster A et al. Objective Comparison Using Guidelinebased Query of Conventional Radiological Reports and Structured Reports. In Vivo 2018; 32: 843-849

[6] Schwartz LH, Panicek DM, Berk AR et al. Improving communication of diagnostic radiology findings through structured reporting. Radiology 2011; 260: 174-181

[7] Bosmans JM, Weyler J], de Schepper AM et al. The radiology report as seen by radiologists and referring clinicians: results of the COVER and ROVER surveys. Radiology 2011; 259: 184-195
[8] Camilo DMR, Tibana TK, Adorno IF et al. Radiology report format preferred by requesting physicians: prospective analysis in a population of physicians at a university hospital. Radiol Bras 2019; 52: 97-103

[9] Barber PA, Demchuk AM, Zhang J et al. Validity and reliability of a quantitative computed tomography score in predicting outcome of hyperacute stroke before thrombolytic therapy. The Lancet 2000; 355: $1670-$ 1674

[10] Wen PY, Macdonald DR, Reardon DA et al. Updated response assessment criteria for high-grade gliomas: response assessment in neurooncology working group. J Clin Oncol 2010; 28: 1963-1972

[11] Pinto Dos Santos D, Baessler B. Big data, artificial intelligence, and structured reporting. Eur Radiol Exp 2018; 2: 42

[12] European Society of R. Good practice for radiological reporting. Guidelines from the European Society of Radiology (ESR). Insights Imaging 2011; 2: 93-96

[13] Morgan TA, Helibrun ME, Kahn CE Jr. Reporting initiative of the Radiological Society of North America: progress and new directions. Radiology 2014; 273: 642-645 